\title{
Microencapsulation of Citral and its Antifungal Activity into Pectin Fillms
}

\author{
Montserrat Calderón-Santoyo ${ }^{1}$ (D) , Maricarmen Iñiguez-Moreno ${ }^{1, *(D)}$, \\ Juan Arturo Ragazzo-Sánchez ${ }^{1, *}$ (D) \\ 1 Integral Laboratory for Food Research, National Technology of Mexico/Technological Institute of Tepic, Tepic, Nayarit, \\ Mexico.montserratcalder@gmail.com (M.C-S.); \\ * Correspondence: jragazzo@tepic.tecnm.mx (J.A.R-S.); mari.moreno2312@gmail.com (M.I-M.); \\ Scopus Author ID 8207779900 (J.A.R-S) \\ Scopus Author ID 57195196153 (M.I-M.)
}

Received: 6.10.2021; Revised: 5.11.2021; Accepted: 8.11.2021; Published: 25.11.2021

\begin{abstract}
Citral is an essential oil with great antimicrobial activity, but its use in the food industry is limited due to its easy decomposition in room conditions. Therefore, this study aimed to microencapsulate citral by the spray drying process and incorporate the powder into pectin films to assess their antifungal activity. For this, solutions of maltodextrin (MD), Arabic gum (AG) sodium alginate (SA) at different concentrations were used to emulsify citral. The emulsion with 10:10:0.1 MD:AG:SA was selected to spray the drying process due to its small droplet size, monomodal size distribution, and low $\mathrm{D}_{[3,2]}, \mathrm{D}_{[4,3]}$, and span index. The dried powder had high solubility $(83.4 \%)$, and low wettability time $(27 \mathrm{~s})$, moisture content $(4.05 \%)$, and bulk density $\left(0.72 \mathrm{~g} / \mathrm{cm}^{3}\right)$, allowing to infer powder stability and showing appropriate handling qualities on a large scale. Thermal analyses reveal that microparticles and pectin films provide thermal protection to citral from 37 to $175^{\circ} \mathrm{C}$. Concerning the antagonistic activity, pectin films added with citral microencapsulated had antifungal activity ranging from 42-68\% against Penicillium italicum, Colletotrichum gloeosporioides, and Aspergillus niger under in vitro conditions. Therefore, these films serve as a basis for developing new edible coatings with practical applications in the postharvest management of phytopathogenic fungi.
\end{abstract}

Keywords: essential oil; spray-drying process; edible films; biopolymers; fungi inhibition.

(C) 2021 by the authors. This article is an open-access article distributed under the terms and conditions of the Creative Commons Attribution (CC BY) license (https://creativecommons.org/licenses/by/4.0/).

\section{Introduction}

Citral is an essential oil (EO) with antifungal, antibacterial, insecticidal, deodorant, and medicinal properties commonly used in the cosmetic and pharmaceutical sectors and a minor amount in the food industry. The use of citral can be limited by its instability at standard conditions, contributing to the loss of the mentioned properties [1]. In addition, this EO is water-insoluble, can modify the food flavor, lose its functional properties when reacting with food components, and could cause toxicity in plant cells [2,3] is necessary to develop alternatives to facilitate its use in the food industry. In this scenario, a spray drying process is an important tool to protect EO's and increase the possibility of its application in postharvest protection. The spray drying process is an alternative for the conversion of an oil-in-water $(\mathrm{O} / \mathrm{W})$ emulsion into a powder, improving the stability, transportation, storage, and enhancing the antifungal activity of an EO [4,5]. For the obtention of microparticles by this technique, several biopolymers have been assessed as wall materials. However, their application at an industrial scale sometimes is limited by their high cost. In line with this, maltodextrin (MD) is 
commonly used as wall material because of its inexpensive cost, neutral taste, capability to generate low viscosity solutions at high concentrations, and provide high protection to encapsulated material against oxidation [6]. The main drawback of MD is the lack of emulsifying activity [7], which is an essential property to consider when formulating an O/W emulsion. Therefore, the emulsifying capability of MD has been improved by blending it with other biopolymers such as Arabic gum (AG) [6]. AG is a biodegradable gum widely used in the food and pharmaceutical industries due to its high solubility, $\mathrm{pH}$ stability, non-toxicity, and gelling properties [8]. However, its high cost, low availability, and chemical heterogeneity caused by different cultivation areas required that industry and researchers find alternatives to AG use [9], such as sodium alginate (SA). SA is a highly branched hydrocolloid [10] with several applications in the food industry, such as texturizer, emulsifier, stabilizer, thickener, and gelling agent. SA has been used in combination with AG for drug encapsulation for its ability to undergo ionic gelation and high viscosity that enable the retention of volatile compounds [11,12]. Besides, to improve the homogeneity of microparticles onto a food surface, the use of a film-forming solution based on natural polymers such as sodium alginate has been proposed to the application of microparticles carvacrol on white mushrooms [4]. Hence, this study aimed to i) formulate an emulsion of citral combining MD:AG:SA, ii) characterize the powder obtained by the spray drying process, and iii) determine the antifungal activity in vitro of pectin films added with citral microencapsulated.

\section{Materials and Methods}

\subsection{Chemical substances.}

Sodium alginate (SA, Food Grade E-401), Arabic gum (AG, Food Grade E-414), and maltodextrin DE 30 (MD; IMSA ${ }^{\circledR}$, Guadalajara, México), miglyol 812 (viscosity $28 \mathrm{cP}$, density $0.940 \mathrm{~g} / \mathrm{mL}$; Sasol Witten, Germany), and citral (density $0.9 \mathrm{~g} / \mathrm{mL}$; Sigma-Aldrich Co., St. Louis, USA) were used for microparticles. For the film, low-methoxyl pectin (29-33\%, Food Grade E-440, Cargill, El Salto, Mexico), calcium chloride (Sigma-Aldrich Co., St. Louis, USA), and glycerol (99.5 \% purity; Jalmek, San Nicolás de los Garza, Mexico) were used.

\subsection{Phytopathogen fungi.}

Colletotrichum gloeosporioides $\mathrm{CpcC}-01$ previously isolated from papaya (Carica papaya L.) [13] and Penicillium italicum S36 (GenBank ID EU128647.1) and Aspergillus niger S24 (GenBank ID GU082483.1) isolated from Persian lime (Citrus latifolia T.) [14] were stored in glycerol $(80 \%, \mathrm{v} / \mathrm{v})$ at $-80{ }^{\circ} \mathrm{C}$ until their use. Before the test, the fungi were cultivated onto Potato Dextrose Agar (PDA, Oxoid, Basingstoke, UK) medium at $28{ }^{\circ} \mathrm{C}$ for 7 days [15].

\subsection{Emulsion preparation.}

The continuous phase of the emulsion was prepared by dissolving SA $(0.1,0.4$, or $0.8 \%$ $\mathrm{w} / \mathrm{v}), \mathrm{AG}(5,7$ or $10 \%, \mathrm{w} / \mathrm{v})$, and $\mathrm{MD}(10 \%, \mathrm{w} / \mathrm{v})$ in distilled water (the amount necessary to reach a volume of $82.5 \mathrm{~mL}$ ) using the magnetic stirrer at $350 \mathrm{rpm}$ for $24 \mathrm{~h}$ at $25 \pm 1{ }^{\circ} \mathrm{C}$, until the solution became clear. Otherwise, the oil phase was prepared, homogenizing $5 \mathrm{~mL}$ miglyol and $12.5 \mathrm{~mL}$ citral for $30 \mathrm{~min}$ at $350 \mathrm{rpm}$. Then the pre-emulsion was prepared by adding the oil phase into the polymeric solution (ratio of oil/continuous phase was 1/5.7) and mixing with an IKA-T10 Basic Ultra Turrax disperser (Janke and Kunkel, Ika-Labortechnick, Germany) 
for $5 \mathrm{~min}$ at $12000 \mathrm{rpm}$. Finally, the pre-emulsion was sonicated at $47 \mathrm{kHz}$ (Digital Sonifier® Unit, Model S-150D, Branson Ultrasonics Corporation, Danbury, CT, USA) for 10 min at 4 ${ }^{\circ} \mathrm{C}$ to obtain the emulsion.

\subsection{Droplet size measurement.}

A laser diffractometer (Mastersizer 3000, Malvern Instruments, Malvern, UK) at $\lambda=$ $633 \mathrm{~nm}$ was used to measure the droplet size distribution of the O/W emulsion. Briefly, 400 $\mathrm{mL}$ distilled water was placed in the measuring cell, and the sample was added dropwise $(\sim 4$ drops) to obtain a 10-12\% laser obscuration. To characterize the droplet size of each emulsion, the distribution curves in volume (\%) vs. droplet diameter, the particle size in function to the cumulative percentage at 50\% $\left(\mathrm{D}_{50}\right)$, surface-weighted mean diameter $\left(\mathrm{D}_{[3,2]}\right.$; Eq. 1$)$, volumeweighted mean particle diameter ( $\mathrm{D}_{[4,3]}$; Eq. 2), and span index (Eq. 3) were obtained.

$$
\begin{aligned}
D_{[3,2]} & =\frac{\sum n_{i} D_{i}^{3}}{\sum n_{i} D_{i}^{2}} \\
D_{[4,3]} & =\frac{\sum n_{i} D_{i}^{4}}{\sum n_{i} D_{i}^{3}}
\end{aligned}
$$

where $n_{i}$ is the number of oil droplets of the size $i$ and $D_{i}$ is droplet diameter.

$$
\text { Span }=\frac{D_{90}-D_{10}}{D_{50}}
$$

$D_{10}, D_{50}$, and $D_{90}$ are the respective diameters at 10,50 , and $90 \%$ of the cumulative droplet distribution or oil volume [7]. The test was carried out at $25 \pm 1{ }^{\circ} \mathrm{C}$ and repeated three times with each sample.

\subsection{Spray drying process.}

A lab-scale spray dryer (Mini Spray Dryer B-290 Büchi, Flawil, Switzerland) with an inlet temperature of $150{ }^{\circ} \mathrm{C}$ was used to dry the emulsion. Briefly, the emulsion was fed with a nozzle $7 \mathrm{~mm}$ in diameter at $35 \mathrm{~m}^{3} / \mathrm{h}$ constant flow rate and air pressure of 4.5 bar; during the process, the emulsion was stirred at $350 \mathrm{rpm}$ at $25{ }^{\circ} \mathrm{C}$. A peristaltic pump at a flow rate of 5 $\mathrm{mL} / \mathrm{min}$. Before drying, the spray dryer was stabilized with sterile distilled water (SDW) under the required operating conditions for $10 \mathrm{~min}$. The powder was stored in PET/BOPP/PE zipper bags at $25 \pm 2{ }^{\circ} \mathrm{C}$.

\subsection{Microparticles characterization.}

\subsubsection{Moisture content (MC).}

The MC was gravimetrically determined [16]. For this, $5 \mathrm{~g}$ of sample were used, and the thermobalance (Sartorius MA 35) was operated at $105{ }^{\circ} \mathrm{C}$; the test was finished until it reached constant weight. The test was carried out by triplicate and repeated twice.

\subsubsection{Water activity $\left(a_{\mathrm{w}}\right)$.}

The measurement was made using $5 \mathrm{~g}$ of the sample in the hygroscopic Aqualab 4TEV (METER Group, Inc., Pullman, USA). The test was carried out in triplicate and repeated twice. 


\subsubsection{Hygroscopicity.}

For the test, $5 \mathrm{~g}$ of the sample were placed at $76 \%$ relative humidity at $21{ }^{\circ} \mathrm{C}$. The samples were weighed every $15 \mathrm{~min}$ for $90 \mathrm{~min}$. The results were expressed as $\mathrm{g}$ of water/100 g of dry solids (Eq. 4).

$$
\mathrm{HG}(\%)=(\Delta \mathrm{m} /(\mathrm{M}+\mathrm{Mi})) /(1+\Delta \mathrm{m} / \mathrm{M})
$$

where $\Delta \mathrm{m}, \mathrm{M}$, and $\mathrm{Mi}$ in grams are the weight gained after the equilibrium, the initial weight of the powder, and the content of free water in the powder before the exposition to a humid environment, respectively [17]. The test was carried out in triplicate and repeated twice.

\subsubsection{Solubility.}

The test was carried out according to the protocol proposed by Cano-Chauca et al. [18]. Briefly, $1 \mathrm{~g}$ of the powder was added in $100 \mathrm{~mL}$ of distilled water and solubilized by stirring at high velocity for $5 \mathrm{~min}$. The sample was centrifugated (Hermle Z326K, Wehingen, Germany) for $5 \mathrm{~min}$ at $3000 \mathrm{~g}, 25 \mathrm{~mL}$ of the supernatant were transferred to pre-weighed Petri dishes and immediately oven-dried at $105^{\circ} \mathrm{C}$ for $5 \mathrm{~h}$. The solubility percentage was calculated by weight difference. The test was carried out in triplicate and repeated twice.

\subsubsection{Bulk density.}

Bulk density value was determined by adding $20 \mathrm{~g}$ of the powder into a $50 \mathrm{~mL}$ graduated cylinder and mixed using a Vortex mixer (Genie 2, Daigger, Wheaton, IL, USA) for 2 min. The bulk density value was calculated by dividing the mass ( $\mathrm{g}$ ) of the powder by the volume $\left(\mathrm{cm}^{3}\right)$. The test was carried out in triplicate and repeated twice.

\subsubsection{Wettability.}

For the test, $1 \mathrm{~g}$ of powder was sprayed onto the surface of $100 \mathrm{~mL}$ of distilled water at $25{ }^{\circ} \mathrm{C}$ under static conditions. The time taken for the particles to disappear from the water surface was used to determine the wettability of the powder [19]. The test was carried out in triplicate and repeated twice.

\subsection{Preparation of films.}

For the preparation of films with and without microparticles, low-methoxyl pectin (1\%, w/v), glycerol $(50 \%, w / w$, on the dry basis to the weight of pectin), and calcium chloride (20 $\mathrm{mg} / \mathrm{g}$ of pectin) were stirring in SDW. When the mixture became clear, $12 \%(\mathrm{w} / \mathrm{v})$ citral microparticles were added to the solution, and the mixture was stirred at $3500 \mathrm{rpm}$ and $25 \pm 2$ ${ }^{\circ} \mathrm{C}$ until its homogenization. The films were obtained by casting method using Petri dishes with a Teflon bottom and let them dry in a biosecurity cabinet (Novatech, Model CFLV-120, Kingwood, USA) for $18 \mathrm{~h}$ at $25 \pm 2{ }^{\circ} \mathrm{C}$.

\subsection{Thermal characterization of microparticles and films.}

Thermogravimetric analysis (TGA) was done using $\sim 6 \mathrm{mg}$ of sample and heating from 25 to $550{ }^{\circ} \mathrm{C}$, at a heating rate of $5{ }^{\circ} \mathrm{C} / \mathrm{min}$ under inert atmosphere (nitrogen at flow rate 40 $\mathrm{mL} / \mathrm{min}$ ) in a TGA 550 equipment (TA Instruments, New Castle, USA) [20]. The derivative thermogravimetric (DTG) curve was obtained directly from the TGA and was used to show the 
weight change. The obtained data were used to calculate the encapsulation efficiency (EE\%, Eq. 5)

$$
E E(\%)=\frac{W_{E O f}}{W_{E O i}} 100
$$

where $W_{E O f}$ is the total weight of EO loaded in the microcapsules and $W_{E O i}$ is the total weight of EO added in the emulsion [21].

Differential scanning calorimetry (DSC) was used to determine the thermal transitions of the samples using a DSC 250 analyzer (TA Instruments, New Castle, USA). For this, 5 mg of sample were placed into aluminum pans (volume $30 \mu \mathrm{L}$ ) and were hermetically sealed. Samples were heated from 25 to $400{ }^{\circ} \mathrm{C}$ at a heating rate of $10{ }^{\circ} \mathrm{C} / \mathrm{min}$, under a nitrogen atmosphere (flow rate of $50 \mathrm{~mL} / \mathrm{min}$ ) [20]. The glass transition temperature $\left(\mathrm{T}_{\mathrm{g}}\right)$, specific heat capacity variation $(\Delta \mathrm{Cp})$, and melting temperature $\left(\mathrm{T}_{\mathrm{m}}\right)$ values were determined using the software TRIOS 5.0.0.44616 (TA Instruments Universal Analysis, New Castle, USA). Thermal tests were performed with the components of the microparticles and films (MD, AG, SA, miglyol, citral, and calcium chloride). Calibration was performed using an indium sample and an empty hermetically sealed aluminum pan was used as a reference in each test. All samples were analyzed twice.

\subsection{Antifungal activity of films added with microparticles of citral.}

The effect of pectin films containing or not microparticles with citral was assessed against $C$. gloeosporioides, $P$. italicum, and $A$. niger. For this, the PDA medium was inoculated with mycelial plugs $(7 \mathrm{~mm})$ of the active growth of each fungus previously cultivated on PDA at $28{ }^{\circ} \mathrm{C}$ for 7 days. Then, the inoculated medium was covered with the films, and the Petri dishes were sealed with parafilm to prevent dehydration. The plates were incubated for 7 days at $28{ }^{\circ} \mathrm{C}$. Inoculated but uncoated medium and PDA added with citral $(12.5 \%$, v/v) were used as positive and negative controls to fungal growth, respectively [22]. The inhibition of mycelial growth was calculated according to Eq. 6:

$$
\text { Inhibition }(\%)=\left(\frac{d c-d t}{d c}\right) 100
$$

where $d c$ and $d t$ are the means of the colony diameter in centimeters for the control and treatment, respectively. The test was carried out in triplicate and repeated twice.

\subsection{Statistical analysis.}

One-way analysis of variance (ANOVA) was used for data processing. Previous to the ANOVA, percentages data were arcsine-square-root transformed. The statistical analysis was performed using the software Statgraphics Centurion XVI.I (Statpoint Technologies, Inc., Warrenton, USA), the post-hoc least significant difference (LSD) Fisher test $(p \leq 0.05)$ was used for means comparison.

\section{Results and Discussion}

\subsection{Emulsion droplet size.}

Citral is an essential oil with great antifungal and deodorant properties; however, its use in the food industry is limited due to its high susceptibility to environmental conditions such as acid, photochemical, and oxidative degradation, resulting in the loss of its properties under standard storage conditions [3,23]. Several alternatives such as emulsions [1,7], microparticles 
[24], and nanofibers [25] have been demonstrated to protect citral. Emulsions are an alternative to microencapsulate, solubilize, and protecting compounds from adverse environmental conditions [1]. Besides, developing an emulsion or solution is the first step to obtaining microparticles by spray drying. The emulsions assessed in this study were prepared in two steps. In the first step, the coarse emulsion was obtained, then the droplet size was reduced by acoustic cavitation and pressure fluctuations generated by ultrasound [1]. In general, the droplet size of the emulsions ranged from 0.1 to $700 \mu \mathrm{m}$. All of them showed a bimodal distribution (Figure 1).

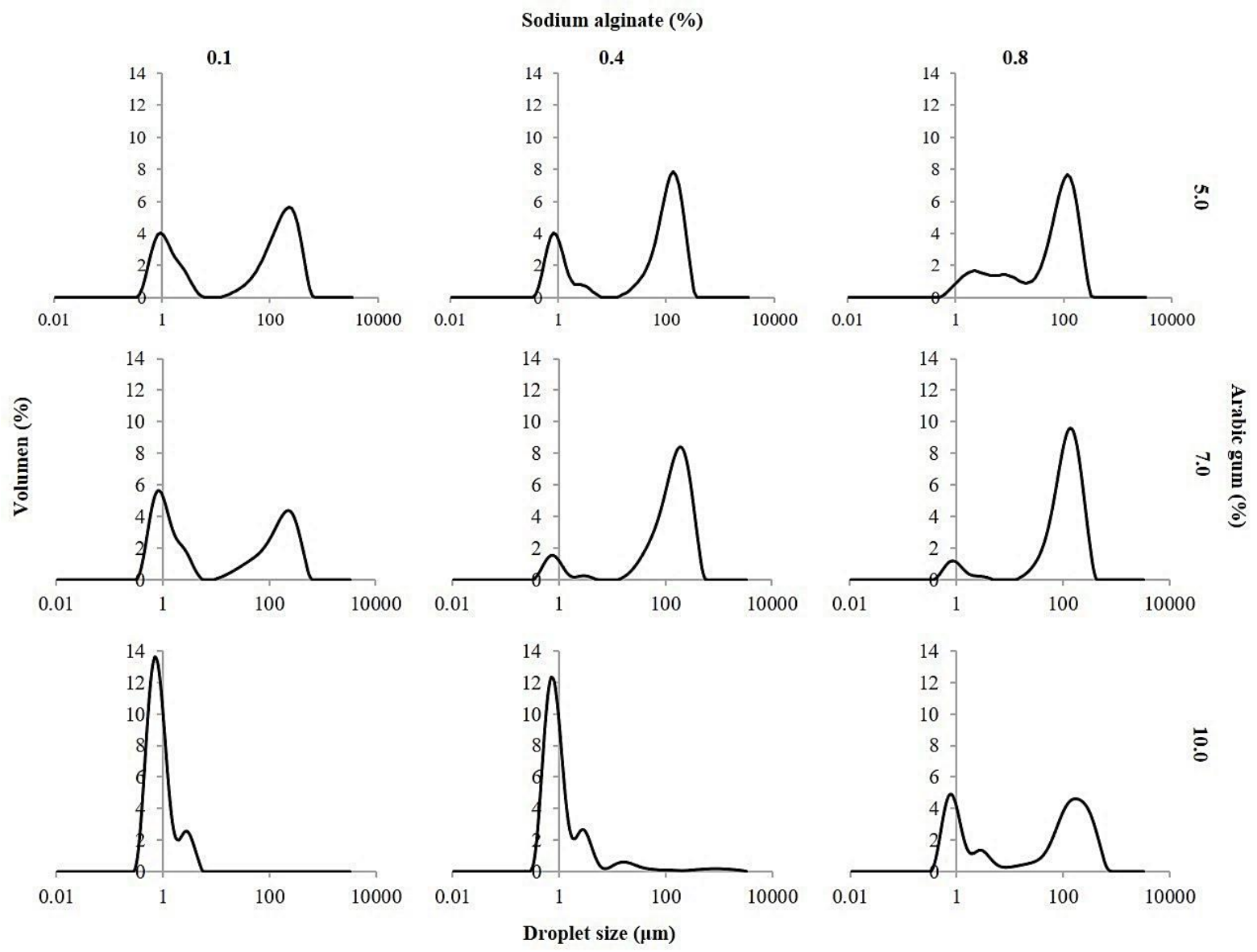

Figure 1. Droplet size distribution profile (in volume, \%) of citral emulsions processed by ultrasound at different concentrations of sodium alginate and Arabic gum. All emulsions contain maltodextrin (10\%, w/v).

Otherwise, the emulsions with $10 \% \mathrm{AG}$ and 0.1 or $0.4 \%$ SA showed almost a monomodal distribution with sizes ranging from 0.01 to $7 \mu \mathrm{m}$, with $\mathrm{D}_{50}$ at $0.89 \mu \mathrm{m}$ (Figure 1, Table 1). The distribution and droplet size of these emulsions can be associated with the AG:SA ratio, which was higher in these formulations in comparison to the other assessed emulsions. These results agree with the previously reported by Miss-Zacarías et al. (2020) to AG:SA emulsions added with citral, in which the droplet ranged from 0.9 to $2.7 \mu \mathrm{m}$. At low AG concentrations, droplets from a weak gel-like network throughout the continuous phase and contribute to phase separation [26]. As the AG concentration increases, increase the presence of arabinogalactan proteins, these are the main ones responsible for stabilizing the properties of AG [27]. Moreover, the absorption of oil molecules is slower in a polysaccharide with a high polymerization degree compared to the use of smaller polymers such as whey protein isolated. In addition to this, the board size ranges obtained in the different emulsions can be related to droplet aggregation [28]. 
Moreover, the small droplet size and almost monomodal distributions of emulsions with higher ratio AG:SA are related to their low values of $\mathrm{D}_{[3,2]}, \mathrm{D}_{[4.3]}$, and span index (Table 1). $D_{[3,2]}$ value is inversely related to the specific surface area of droplets and indicates the mean diameter at which most of the particles fall. Otherwise, the $\mathrm{D}_{[4,3]}$ index has a greater sensitivity to determine the presence of larger droplets or droplet size changes [29]. High values of these parameters are associated with destabilization mechanisms such as emulsion flocculation or coalescence [1]. On the other hand, low values are related to i) the homogenization process $[1,30]$, ii) the composition of the dispersant phase [29,31], and iii) the concentration of biopolymer in the formulation [32]. The variability of the parameters between the emulsions obtained in this research is related to the changes in the concentration of the biopolymers in each formulation. As the concentration of biopolymers increases, small droplets can be obtained due to the high availability of wall materials to encapsulate the core material, decreasing in specific surface area value [32].

Table 1. Droplet size of emulsions with different biopolymer concentration.

\begin{tabular}{c|c|c|c|c|c}
$\begin{array}{c}\text { Arabic gum } \\
\text { w/v })\end{array}$ & $\begin{array}{c}\text { Sodium alginate } \\
(\%, \mathrm{w} / \mathrm{v})\end{array}$ & $\mathrm{D}_{50}(\mu \mathrm{m})$ & $\mathrm{D}_{[3,2]}$ & $\mathrm{D}_{[4,3]}$ & \multirow{2}{*}{ Span } \\
\hline \multirow{3}{*}{5} & 0.1 & $87.40 \pm 9.35^{\mathrm{b}}$ & $2.75 \pm 0.03^{\mathrm{e}}$ & $122 \pm 0.03^{\mathrm{d}}$ & $3.62 \pm 0.11^{\mathrm{f}}$ \\
\cline { 2 - 6 } & 0.4 & $83.90 \pm 3.23^{\mathrm{b}}$ & $3.00 \pm 0.03^{\mathrm{d}}$ & $89.4 \pm 0.01^{\mathrm{g}}$ & $2.37 \pm 0.10^{\mathrm{h}}$ \\
\cline { 2 - 6 } & 0.8 & $78.70 \pm 1.84^{\mathrm{c}}$ & $2.22 \pm 0.06^{\mathrm{f}}$ & $78.8 \pm 0.08^{\mathrm{i}}$ & $4.01 \pm 0.03^{\mathrm{d}}$ \\
\hline \multirow{3}{*}{7} & 0.1 & $20.90 \pm 1.66^{\mathrm{d}}$ & $1.90 \pm 0.01^{\mathrm{g}}$ & $93.7 \pm 0.02^{\mathrm{f}}$ & $16.00 \pm 0.92^{\mathrm{b}}$ \\
\cline { 2 - 6 } & 0.4 & $111.00 \pm 2.59^{\mathrm{a}}$ & $6.96 \pm 0.00^{\mathrm{b}}$ & $152 \pm 0.02^{\mathrm{a}}$ & $2.18 \pm 0.04^{\mathrm{i}}$ \\
\cline { 2 - 6 } & 0.8 & $117.00 \pm 2.41^{\mathrm{a}}$ & $9.80 \pm 0.02^{\mathrm{a}}$ & $126 \pm 0.04^{\mathrm{c}}$ & $1.79 \pm 0.012^{\mathrm{j}}$ \\
\hline \multirow{2}{*}{10} & 0.1 & $0.88 \pm 0.00^{\mathrm{e}}$ & $0.79 \pm 0.01^{\mathrm{h}}$ & $1.09 \pm 0.001^{\mathrm{h}}$ & $2.20 \pm 0.07^{\mathrm{a}}$ \\
\cline { 2 - 6 } & 0.4 & $0.89 \pm 0.02^{\mathrm{e}}$ & $0.89 \pm 0.00^{\mathrm{de}}$ & $24.00 \pm 0.01^{\mathrm{d}}$ & $4.11 \pm 0.01^{\mathrm{c}}$ \\
\cline { 2 - 6 } & 0.8 & $70.00 \pm 9.46^{\mathrm{c}}$ & $4.43 \pm 0.05^{\mathrm{c}}$ & $129 \pm 0.05^{\mathrm{b}}$ & $3.31 \pm 0.05^{\mathrm{g}}$
\end{tabular}

All emulsions contain $10 \%(\mathrm{w} / \mathrm{v})$ maltodextrin. Values in the same column followed by different lower-case letters are significantly different according to Fisher's LSD test at $p<0.05$.

Based on these results, the emulsion composed of $10 \% \mathrm{MD}, 10 \% \mathrm{AG}$, and $0.1 \% \mathrm{SA}$ (ratio of polysaccharides in the emulsion 1:1:0.1, MD:AG:SA) was selected to obtain microparticles by the spray drying process. Because the values obtained for the assessed parameters suggested, that can be a stable emulsion and enables the obtention of microparticles with a high surface area to volume ratio. From a biological point of view, these structures have an optimal diffusion capacity, facilitating the interaction with the target microorganism compared to large particles [33]. Besides, the obtention of small particles reduces the volume of the powder, which is appropriate for the transport and packaging of the final product [34]. Otherwise, this emulsion has a similar droplet size to the emulsion with $0.4 \%$ SA with a low amount of this biopolymer (Table 1).

\subsection{Microparticles characterization.}

Bulk density, MC, solubility, wettability, and $\mathrm{a}_{\mathrm{w}}$ are important properties for ease of reconstitution and stability of a powder. The bulk density is a significant factor in the transportation, storage, packing, and mixing of food products [35]. The bulk density of the powder was $0.72 \pm 0.14 \mathrm{~g} / \mathrm{cm}^{3}$. This value is higher than the reported pectin/sodium alginate microparticles added with carvacrol $\left(\sim 0.34 \mathrm{~g} / \mathrm{cm}^{3}\right)$ at $160{ }^{\circ} \mathrm{C}$ inlet air temperature. The difference between the studies is related to polymers with a high polymerization degree, increasing the value of this property [4,9]. Otherwise, bulk density is mainly associated with the inlet temperature. High inlet air temperatures favor low values for this parameter because the increase in the air temperature results in a droplet surface hardening [36]. Besides, high 
inlet air temperatures increase the evaporation rate, leading to less shrinkage of the droplets consequentially in a less dense powder [37].

Citral microparticles showed an MC of $4.05 \pm 0.18 \%$. Previously, it was reported an $\mathrm{MC}$ ranged from 4 to $6.6 \%$ to citral in microparticles of dextrin [24]. MC in microparticles is highly related to inlet temperature; as the temperature increases, the MC can decrease. In addition, the binding properties of the biopolymers also affect this value. The possible development of a complex between the SA, AG, and citral decreases the sites to binding water sites. Low MC is a positive characteristic insight of long storage of this kind of product [38]. Besides, an MC lower than 5\% is optimal to control microbial contamination and prevent lipid oxidation [39]. Otherwise, $a_{w}$ is an important property in spray-dried powders because it affects the shelf life of the foods [40]. The $\mathrm{a}_{\mathrm{w}}$ of SA/AG microparticles with citral was $0.18 \pm 0.03$. In general, natural products or foods with $\mathrm{a}_{\mathrm{w}}$ lower than 0.6 are considered microbiologically stable [40]. The $\mathrm{a}_{\mathrm{w}}$ and $\mathrm{MC}$ in a spray-dried powder greatly depend on the wall materials and inlet temperature [38]. In line with this, the microparticles showed high solubility in water (83.4 $\pm 2.8 \%$ ). This value was expected since materials used in the spray drying processes have high solubility, in SA and AG, attributable to their hydrophilic properties [41]. Otherwise, AG is composed of polysaccharide fractions and glycoproteins rich in amino acid residues of hydroxyproline, proline, and serine that provide a water solubility up to $50 \%(\mathrm{w} / \mathrm{v}$ ) [42].

Another important characteristic in powders is wettability, which refers to the time required for the microparticles to completely wet [43]. The wettability of MD:AG:SA microparticles was $27.07 \pm 8.22$ s. Previously was reported that the wettability of microparticles of AG and MD with sumac extract was 167 and 305 s, respectively [6]; while to AG $(10 \%$, w/w) microparticles with kuini powder was $236.67 \pm 34.03 \mathrm{~s}$, both studies used $150{ }^{\circ} \mathrm{C}$ inlet temperature [35]. It has been reported that the wettability varies in function to the inlet temperature; at low temperatures, the percentage of small particles increases, reducing the void spaces between particles and increasing the resistance to water transfer [6]. Moreover, the properties of wall materials also affect the wettability of microparticles, and the discrepancy with other studies could be related to the presence of hydrophilic groups $(\mathrm{OH}$ and $\mathrm{COOH})$ in the biopolymers [9]. Finally, moisture adsorption of the microparticles powder after $180 \mathrm{~min}$ in an atmosphere with $76 \%$ of $\mathrm{RH}$ was $26.7 \pm 0.2 \%(\mathrm{w} / \mathrm{w})$. This value is higher than the previously reported microparticles of pectin/sodium alginate with carvacrol $(11 \%, \mathrm{w} / \mathrm{w})$ after 90 min [39]. Particles obtained by the spray drying process will absorb ambient humidity, the content of absorbed water will increase with the time exposition [44]. Moreover, the wall materials properties and low water content also affect this parameter due to hygroscopicity increasing as water content decrease [39].

\subsection{Thermal analyses of microparticles and pectin films with citral microencapsulated.}

The thermal profiles of microparticles and films added with microparticles with citral were studied by TGA and DSC (Figure 2). Citral mass decreased $97.15 \%$ from 25 to $150{ }^{\circ} \mathrm{C}$, and this result is in agreement with literature observations [7,45]. Its decomposition at environmental temperatures shows the necessity to protect EOs like this. The thermal decomposition of all non-biopolymeric components of microparticles and films occurred in one step (Figure 2A). Otherwise, the mass variation of biopolymers (MD, SA, AG, and pectin) showed two steps; the first step $\left(25-130{ }^{\circ} \mathrm{C}\right)$ correspond to the loss of moisture and linked water [20], the amount ranged from 4 to $15 \%$ depending on each biopolymer and their hygroscopic properties [46]. The second step, located between 129 and $370{ }^{\circ} \mathrm{C}$ indicates the decomposition 
of the polysaccharide chain. The presence of glycoproteins in the AG increases the temperature of decomposition of this biopolymer [34].
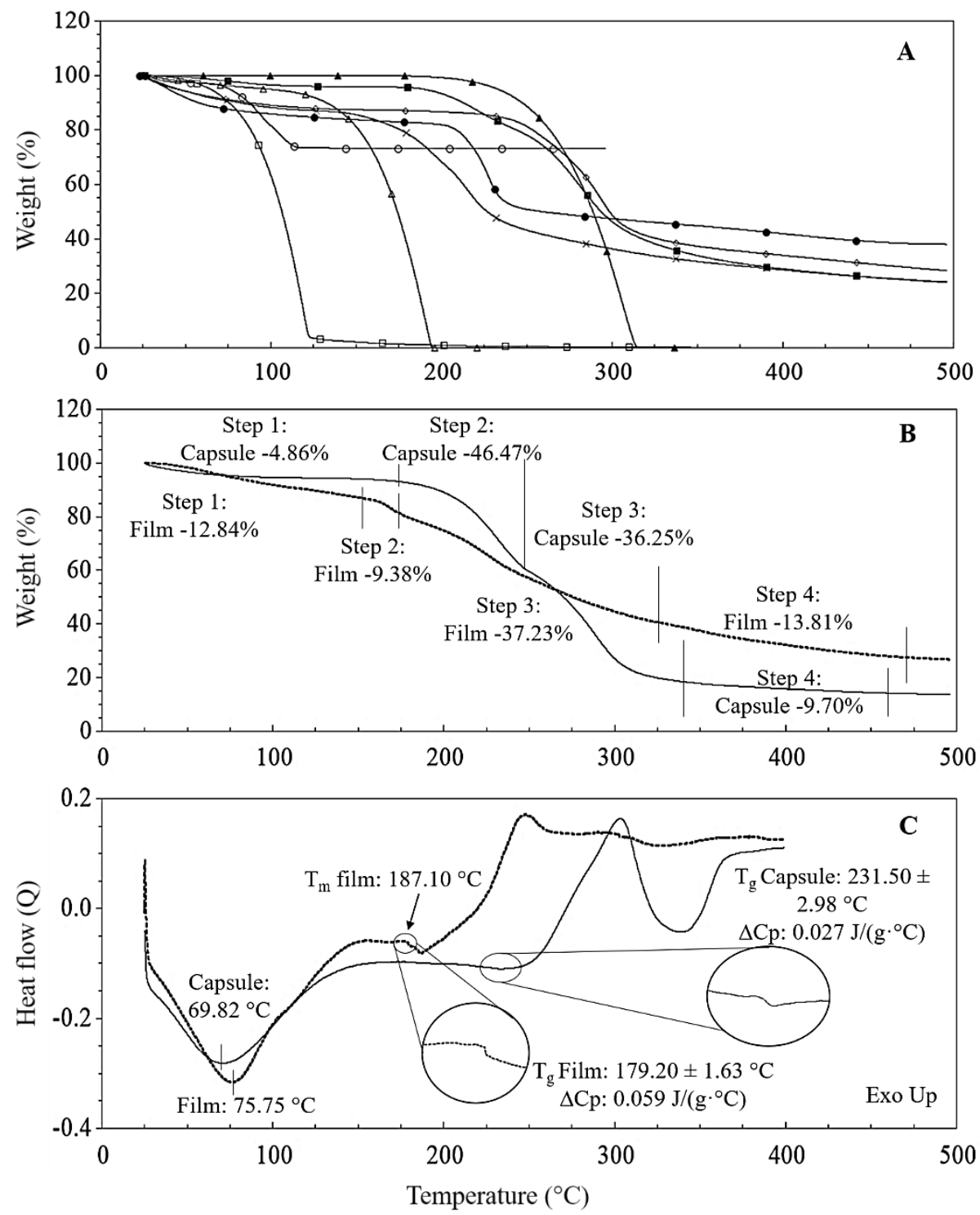

Figure 2. Thermal analyses of microparticles and pectin films added with citral microencapsulated. (A) Thermogravimetry (TG) curves components of microparticles and films (glycerol $\Delta$; citral $\square$; miglyol $\mathbf{\Delta}$; calcium chloride $\circ$; maltodextrin $\mathbf{\square}$; Arabic gum $\diamond$; sodium alginate $\bullet$; pectin $\times$. Markers are used for readers' guidance, do not represent a particular measure). (B) TG and (C) differential scanning calorimetry curves of microparticles with citral (-) and pectin films added with citral microencapsulated (--).

The TGA of microparticles and films showed a decomposition in four steps. The first step, which was located between 25 and $125^{\circ} \mathrm{C}$ and 25 and $150{ }^{\circ} \mathrm{C}$ to microparticles and films, was associated with the loss of moisture, physically bound water, and the volatile fraction of the non-encapsulated oil [4]. The weight loss in this step agrees with the MC results (Section 3.2). The second weight-loss located between 150-188 and $125-250{ }^{\circ} \mathrm{C}$ and to films and microparticles, respectively (Figure $2 \mathrm{~B}$ ), was related to the depolymerization process and thermal degradation of the wall material of microparticles and oil phase decomposition $[7,9]$. The third mass loss between $188-330$ and $250-345^{\circ} \mathrm{C}$ to films and microparticles correspond to the second mass loss in the biopolymers (AG, MD, and pectin; Figure 2A). Finally, the fourth loss in both samples was associated with the decomposition of carbonaceous material [47]. The absence of mass loss in microparticles 115 and $150{ }^{\circ} \mathrm{C}$, suggested the encapsulation of citral and the thermal protection of the EO by the microparticles. Besides, the EE\% estimated 
by TGA was $31.73 \%$. Similar results were previously reported to the use of solid lipid nanoparticles [45], AG:SA emulsion [7], and electrospun nanofibers of cyclodextrins [25] to the protection of citral. However, higher EE\% (76-90\%) has been obtained for sesame oil encapsulated in mixtures of mesquite gum and MD DE10 at different ratios. The discrepancies between the studies can be related to the amount of EO, nature and amount of wall material, and inlet temperature [48].

DSC is a potent technique for observing physical and chemical changes in polysaccharides as they undergo heat processing. Microparticles and films exhibited a broad endothermic peak with the mean temperature at 69.82 and $75.75{ }^{\circ} \mathrm{C}$ to microparticles and films, respectively. These broad peaks were assigned with the loss of moisture, crystallized water, hydrogen-bonded water, and other physically adsorbed water [49]. The difference of $\sim 6{ }^{\circ} \mathrm{C}$ in the midpoint of the peaks can be related to the binding mode of water in different samples, which required more or less energy to release it [50]. Besides, the discrepancy can be related to the higher MC of films compared to microparticles (Figure 2C). This fact, the addition of pectin and glycerol to develop the films, and the increment of water content produced a decrement in the $T_{g}$ value in films compared to the obtained in the microparticles. However, in both cases, one $\mathrm{T}_{\mathrm{g}}$ value was obtained, allowing us to infer the miscibility of all materials [29]. The high $\mathrm{T}_{\mathrm{g}}$ values (179.20 and $231.50^{\circ} \mathrm{C}$ to films and microparticles, respectively) are critical in developing dry powders and food packaging. Powders and films with a low $\mathrm{T}_{\mathrm{g}}$ are prone to stickiness and caking phenomena (the last one in the powder), with negative consequences on their stability, textural, chemical, and sensory quality [51]. Otherwise, the $T_{m}$ value agrees with the onset temperature of film decomposition obtained by TGA (Figure 2B). The exothermic at 248 and $302{ }^{\circ} \mathrm{C}$ in films and microparticles, respectively, correspond to the decomposition of the biopolymers in the formulation. Depolymerization reactions are associated with the incomplete decarboxylation of the $\mathrm{COOH}$ groups and oxidation reactions of the polyelectrolytes groups in polysaccharides [49]. Finally, the exothermic event at $360{ }^{\circ} \mathrm{C}$ corresponds to the decomposition of the carbonaceous material (Figure 2C) [20,49].

\subsection{In vitro antifungal activity of films.}

The results of the fungi inhibition with films added with microparticles with citral are shown in Table 2. The use of pectin films without microparticles favored the growth of the fungi and increased their growth by $\sim 18 \%$ concerning the controls (Figure 3 ). Due to the fungi can synthesize pectinases and use the biopolymer as a carbon source for their growth [52]. However, pectin films added with citral microencapsulated significantly affected the inhibition of fungi growth (42-68\%, Table 2) under assessed conditions.

The antifungal activity of pectin films was mainly attributable to the presence of the EO. It estimated concentration in the pectin films based on the loading efficiency and bulk density was $0.6 \mu \mathrm{L} / 100 \mathrm{~mL}$ of film-forming solution. Antifungal activity of citral could be explained in two ways; the first is that the monoterpenes (citral and geraniol) can cross the fungi membrane and interact with enzymes and proteins, producing its disruption. This event leads to morphological changes in the plasma membrane producing the loss of cytosol components resulting in fungal cell death $[53,54]$. The second antagonist mechanism of citral is the alteration of the mitochondrial morphology, resulting in reduced ATP content and inhibition of the tricarboxylic acid cycle (TCA) [55]. These mechanisms were demonstrated against $P$. italicum with citral concentration ranging from 0.50 to $1.0 \mu \mathrm{L} / \mathrm{mL}$, in which the 
disruption of membrane integrity was due to the decrement of ergosterol and total lipid content [56].

Table 2. Fungi inhibition with films added with citral.

\begin{tabular}{c|c|c}
\multirow{2}{*}{ Fungi } & \multicolumn{2}{|c}{ Percentage inhibition } \\
\cline { 2 - 3 } & Citral $(0.125 \mu \mathrm{L} / \mathrm{mL})$ & $\begin{array}{c}\text { Film with citral } \\
\text { microencapsulated }\end{array}$ \\
\hline Colletotrichum gloeosporioides & $100.0 \pm 0.0^{\mathrm{Aa}}$ & $42.9 \pm 2.3^{\mathrm{Cb}}$ \\
\hline Penicillium italicum & $100.0 \pm 0.0^{\mathrm{Aa}}$ & $68.3 \pm 2.8^{\mathrm{Ab}}$ \\
\hline Aspergillus niger & $100.0 \pm 0.0^{\mathrm{Aa}}$ & $54.7 \pm 1.6^{\mathrm{Bb}}$
\end{tabular}

Values are expressed as means \pm standard deviation $(n=6)$. Values in the same column followed by different capital-case letters are significantly different according to Fisher's LSD test at $p<0.05$. Values in the same row followed by different lower-case letters are significantly different according to Fisher's LSD test at $p<0.05$.

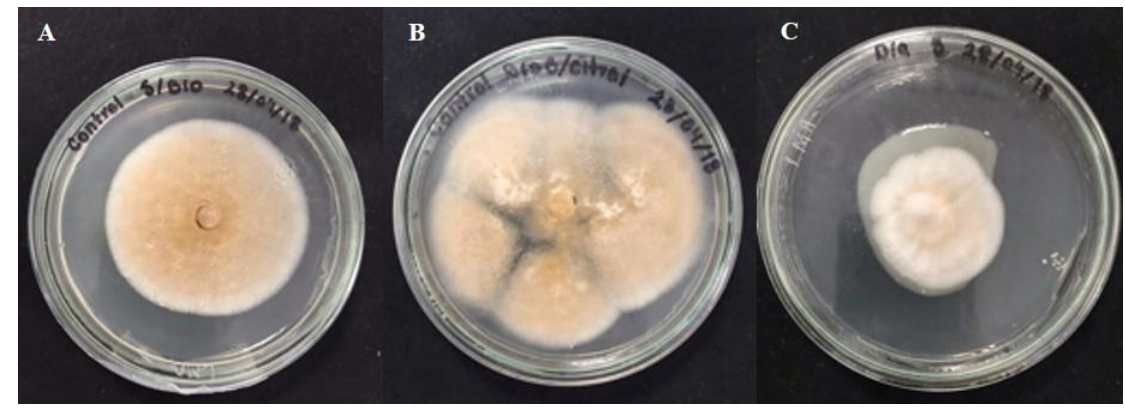

Figure 3. Growth inhibition of Colletotrichum gloeosporioides with pectin films added with citral microencapsulated. (A) C. gloeosporioides without film, and covered with pectin films (B) without and (C) with citral microencapsulated after 8 days of incubation at $28{ }^{\circ} \mathrm{C}$.

Otherwise, in Aspergillus spp. was demonstrated that citral increased cell membrane permeability led to the leakage of intracellular constituents reaching $100 \%$ of inhibition at 0.5 $\mu \mathrm{L} / \mathrm{mL}$. Besides, citral and geranial can induce the synthesis of reactive oxygen species (ROS) in Aspergillus spp. rapidly [57]. High ROS levels reduce the concentration of intracellular antioxidants and alter DNA and proteins' structure, resulting in cell damage or apoptosis. The mechanism of microbial inactivation by ROS assumed that ROS involved the formation of Fenton-mediated hydroxyl radicals through the TCA cycle and ultimately initiated cell death [58]. In addition to citral activity, the films represent a physical barrier to oxygen generated by the films that produce a depletion in their concentration, reducing its availability to fungal metabolism [59]. Therefore, the microencapsulation of citral and the films allowed fungal inhibition using a lower amount of the EO compared to other studies [57,60]. Contributing to using natural resources to develop edible coatings with active properties is a current necessity in the food packaging industry.

\section{Conclusions}

In this study, several emulsions with MD (10\%) and different concentrations of AG and SA were assessed. Based on the droplet size, the higher volume of small droplets, and monomodal distribution, the emulsion with the higher ratio AG:SA 1:0.1 (ratio of all polysaccharides in the emulsion 1:1:0.1 to MD:AG:SA) was selected for the spray drying process. The powder obtained after the drying process had high solubility, and low wettability time, MC, and bulk density is allowing us to infer powder stability and easy handling at a large scale. Besides, the thermal analyses reveal that microparticles and pectin films give thermal protection to citral, and the high $\mathrm{T}_{\mathrm{g}}$ values obtained contribute to reducing the possibility of the loss of nanofiber properties during their storage alone or into the films. Regarding the antagonistic activity, pectin films added with citral microencapsulated were able to control the 
fungal growth of $P$. italicum, $C$. gloeosporioides, and A. niger under in vitro conditions. Therefore, these films provide a basis for developing edible coatings with active properties with feasible applications in the postharvest management of phytopathogenic fungi. However, further studies should be carried out on the full characterization of the film and assess its effect on phytopathogenic fungi in vivo conditions and on the organoleptic properties of the fruits.

\section{Funding}

This research was funded by CONACYT (Consejo Nacional de Ciencia y Tecnología-Mexico) for their support through the project 316948 . This study was supported by the CYTED thematic network code 319RT0576.

\section{Acknowledgments}

The authors thank CONACYT (Consejo Nacional de Ciencia y Tecnología-Mexico) postdoctoral grant awarded to Maricarmen Iñiguez-Moreno [740456] and for the support through FOP02-2021-04-316948.

\section{Conflicts of Interest}

The authors declare no conflict of interest. The funders had no role in the study's design, in the collection, analyses, or interpretation of data, in the writing of the manuscript, or in the decision to publish the results.

\section{References}

1. Lu, W.C.; Huang, D.W.; Wang, C.C.R.; Yeh, C.H.; Tsai, J.C.; Huang, Y.T.; Li, P.H. Preparation, characterization, and antimicrobial activity of nanoemulsions incorporating citral essential oil. J. Food Drug Anal. 2018, 26, 82-89, https://doi.org/10.1016/j.jfda.2016.12.018.

2. Acevedo-Fani, A.; Soliva-Fortuny, R.; Martín-Belloso, O. Nanoemulsions as edible coatings. Curr. Opin. Food Sci. 2017, 15, 43-49, https://doi.org/10.1016/j.cofs.2017.06.002.

3. Prakash, A.; Baskaran, R.; Vadivel, V. Citral nanoemulsion incorporated edible coating to extend the shelf life of fresh cut pineapples. LWT - Food Sci. Technol. 2020, 118, 108851, https://doi.org/10.1016/j.lwt.2019.108851.

4. Cheng, M.; Wang, J.; Zhang, R.; Kong, R.; Lu, W.; Wang, X. Characterization and application of the microencapsulated carvacrol/sodium alginate films as food packaging materials. Int. J. Biol. Macromol. 2019, 141, 259-267, https://doi.org/10.1016/j.ijbiomac.2019.08.215.

5. Macías-Cortés, E.; Gallegos-Infante, J.A.; Rocha-Guzmán, N.E.; Moreno-Jiménez, M.R.; Medina-Torres, L.; González-Laredo, R.F. Microencapsulation of phenolic compounds: Technologies and novel polymers. Rev. Mex. Ing. Quim. 2020, 19, 491-521, https://doi.org/10.24275/rmiq/Alim642.

6. Lourenço, S.C.; Moldão-Martins, M.; Alves, V.D. Microencapsulation of pineapple peel extract by spray drying using maltodextrin, inulin, and Arabic gum as wall matrices. Foods 2020, 9, 718, https://doi.org/10.3390/foods9060718.

7. Miss-Zacarías, D.M.; Iñiguez-Moreno, M.; Calderón-Santoyo, M.; Ragazzo-Sánchez, J.A. Optimization of ultrasound-assisted microemulsions of citral using biopolymers: characterization and antifungal activity. $J$. Dispers. Sci. Technol. 2020, O, 1-10, https://doi.org/10.1080/01932691.2020.1857264.

8. Gils, P.S.; Ray, D.; Sahoo, P.K. Designing of silver nanoparticles in gum arabic based semi-IPN hydrogel. Int. J. Biol. Macromol. 2010, 46, 237-244, https://doi.org/10.1016/j.ijbiomac.2009.12.014.

9. Campos Toledo, A.A.; Gomes, J.M.; Silva, E.K.; Machado, V.; Yoshida, M.I.; Vilela, S. Understanding the influence of encapsulating matrix on the physical and thermal properties of oregano essential oil powder. Int. J. Hortic. Agric. 2017, 2, 1-8, https://doi.org/10.15226/2572-3154/2/1/00109.

10. Parreidt, T.S.; Schott, M.; Schmid, M.; Müller, K. Effect of presence and concentration of plasticizers, vegetable oils, and surfactants on the properties of sodium-alginate-based edible coatings. Int. J. Mol. Sci. 2018, 19, 742, https://doi.org/10.3390/ijms19030742.

11. Zheng, J.; Zeng, R.; Zhang, F.; Kan, J. Effects of sodium carboxymethyl cellulose on rheological properties and gelation behaviors of sodium alginate induced by calcium ions. LWT - Food Sci. Technol. 2019, 103, 131-138, https://doi.org/10.1016/j.lwt.2018.12.081. 
12. Emamifar, A.; Bavaisi, S. Nanocomposite coating based on sodium alginate and nano-ZnO for extending the storage life of fresh strawberries (Fragaria $\times$ ananassa Duch.). J. Food Meas. Charact. 2020, 14, 10121024, https://doi.org/10.1007/s11694-019-00350-x.

13. Sandoval-Contreras, T.; Iñiguez-Moreno, M.; Garrido-Sánchez, L.; Ragazzo-Sánchez, J.A.; Narváez-Zapata, J.A.; Ascencio, F.; Calderón-Santoyo, M. Predictive model for the effect of environmental conditions on the postharvest development of Colletotrichum gloeosporioides strains isolated from papaya (Carica papaya L.). J. Food Prot. 2020, 83, 1495-1504, https://doi.org/10.4315/JFP-19-493.

14. Sandoval-Contreras, T.; Villarruel-López, A.; Torres-Vitela, R.; Garciglia-Mercado, C.; Gómez-Anduro, G.; Velázquez-Lizárraga, A.E.; Sierra-Beltran, A.; Ascencio, F. Mycotoxigenic potential of phytopathogenic moulds isolated from citrus fruits from different states of Mexico. Qual. Assur. Saf. Crop. Foods 2018, 10, 125-136, https://doi.org/10.3920/QAS2016.0890.

15. González-Estrada, R.R.; Chalier, P.; Ragazzo-Sánchez, J.A.; Konuk, D.; Calderón-Santoyo, M. Antimicrobial soy protein based coatings: Application to Persian lime (Citrus latifolia Tanaka) for protection and preservation. Postharvest Biol. Technol. 2017, 132, 138-144, https://doi.org/10.1016/j.postharvbio.2017.06.005.

16. AOAC Official Methods of Analysis of AOAC International; Sixteenth.; Association of Analytical Chemists: Washington DC, USA, 1997.

17. Al-Kahtani, H.; Hassan, B. Spray drying of Roselle (Hibiscus sabdariffa L.) extract. J. Food Sci. 1990, 55, 1073-1076, https://doi.org/10.1111/j.1365-2621.1990.tb01601.x.

18. Cano-Chauca, M.; Stringheta, P.C.; Ramos, A.M.; Cal-Vidal, J. Effect of the carriers on the microstructure of mango powder obtained by spray drying and its functional characterization. Innov. Food Sci. Emerg. Technol. 2005, 6, 420-428, https://doi.org/10.1016/j.ifset.2005.05.003.

19. Fuchs, M.; Turchiuli, C.; Bohin, M.; Cuvelier, M.E.; Ordonnaud, C.; Peyrat-Maillard, M.N.; Dumoulin, E. Encapsulation of oil in powder using spray drying and fluidised bed agglomeration. J. Food Eng. 2006, 75, 27-35, https://doi.org/10.1016/j.jfoodeng.2005.03.047.

20. Iñiguez-Moreno, M.; Ragazzo-Sánchez, J.A.; Barros-Castillo, J.C.; Solís-Pacheco, J.R.; Calderón-Santoyo, M. Characterization of sodium alginate coatings with Meyerozyma caribbica and impact on quality properties of avocado fruit. LWT - Food Sci. Technol. 2021, 152, 112346, https://doi.org/10.1016/j.lwt.2021.112346.

21. Rivera-Aguilar, J.O.; Calderón-Santoyo, M.; González-Cruz, E.M.; Ramos-Hernández, J.A.; RagazzoSánchez, J.A. Encapsulation by electrospraying of anticancer compounds from jackfruit extract (Artocarpus heterophyllus Lam): Identification, characterization and antiproliferative properties. Anticancer. Agents Med. Chem. 2021, 21, 1-9, https://doi.org/10.2174/1871520620666200804102952.

22. Iñiguez-Moreno, M.; Ragazzo-Sánchez, J.A.; Barros-Castillo, J.C.; Sandoval-Contreras, T.; CalderónSantoyo, M. Sodium alginate coatings added with Meyerozyma caribbica: Postharvest biocontrol of Colletotrichum gloeosporioides in avocado (Persea americana Mill. cv. Hass). Postharvest Biol. Technol. 2020, 163, 111123, https://doi.org/10.1016/j.postharvbio.2020.111123.

23. Ma, H.; Zhao, Y.; Lu, Z.; Xing, R.; Yao, X.; Jin, Z.; Wang, Y.; Yu, F. Citral-loaded chitosan/carboxymethyl cellulose copolymer hydrogel microspheres with improved antimicrobial effects for plant protection. Int. J. Biol. Macromol. 2020, 164, 986-993, https://doi.org/10.1016/j.ijbiomac.2020.07.164.

24. Yoplac, I.; Vargas, L.; Robert, P.; Hidalgo, A. Characterization and antimicrobial activity of microencapsulated citral with dextrin by spray drying. Heliyon 2021, 7, e06737, https://doi.org/10.1016/j.heliyon.2021.e06737.

25. Aytac, Z.; Celebioglu, A.; Yildiz, Z.I.; Uyar, T. Efficient encapsulation of citral in fast-dissolving polymerfree electrospun nanofibers of cyclodextrin inclusion complexes: High thermal stability, longer shelf-life, and enhanced water solubility of citral. Nanomaterials 2018, 8, 793, https://doi.org/10.3390/nano8100793 .

26. Sun, C.; Gunasekaran, S.; Richards, M.P. Effect of xanthan gum on physicochemical properties of whey protein isolate stabilized oil-in-water emulsions. Food Hydrocoll. 2007, 21, 555-564, https://doi.org/10.1016/j.foodhyd.2006.06.003.

27. Al-Assaf, S.; Sakata, M.; McKenna, C.; Aoki, H.; Phillips, G.O. Molecular associations in acacia gums. Struct. Chem. 2009, 20, 325-336, https://doi.org/10.1007/s11224-009-9430-3.

28. Djordjevic, D.; Cercaci, L.; Alamed, J.; McClements, D.J.; Decker, E.A. Stability of citral in protein- and gum arabic-stabilized oil-in-water emulsions. Food Chem. 2008, 106, 698-705, https://doi.org/10.1016/j.foodchem.2007.06.033.

29. Ruiz-Montañez, G.; Calderón-Santoyo, M.; Chevalier-Lucia, D.; Picart-Palmade, L.; Jimenez-Sánchez, D.E.; Ragazzo-Sánchez, J.A. Ultrasound-assisted microencapsulation of jackfruit extract in eco-friendly powder particles: characterization and antiproliferative activity. J. Dispers. Sci. Technol. 2019, 40, 1507-1515, https://doi.org/10.1080/01932691.2019.1566923.

30. Fioramonti, S.A.; Rubiolo, A.C.; Santiago, L.G. Characterisation of freeze-dried flaxseed oil microcapsules obtained by multilayer emulsions. Powder Technol. 2017, 319, 238-244, https://doi.org/10.1016/j.powtec.2017.06.052.

31. Ramos-Bell, S.; Calderón-Santoyo, M.; Barros-Castillo, J.C.; Ragazzo-Sánchez, J.A. Characterization of submicron emulsion processed by ultrasound homogenization to protect a bioactive extract from sea grape (Coccoloba uvifera L.). Food Sci. Biotechnol. 2020, https://doi.org/10.1007/s10068-020-00780-0. 
32. Akdeniz, B.; Sumnu, G.; Sahin, S. The effects of maltodextrin and gum Arabic on encapsulation of onion skin phenolic compounds. Chem. Eng. Trans. 2017, 57, 1891-1896, https://doi.org/10.3303/CET1757316.

33. de Vos, P.; Faas, M.M.; Strand, B.; Calafiore, R. Alginate-based microcapsules for immunoisolation of pancreatic islets. Biomaterials 2006, 27, 5603-5617, https://doi.org/10.1016/j.biomaterials.2006.07.010.

34. Kang, Y.R.; Lee, Y.K.; Kim, Y.J.; Chang, Y.H. Characterization and storage stability of chlorophylls microencapsulated in different combination of gum Arabic and maltodextrin. Food Chem. 2019, 272, 337346, https://doi.org/10.1016/j.foodchem.2018.08.063.

35. Caliskan, G.; Nur Dirim, S. The effects of the different drying conditions and the amounts of maltodextrin addition during spray drying of sumac extract. Food Bioprod. Process. 2013, 91, 539-548, https://doi.org/10.1016/j.fbp.2013.06.004.

36. Greenwald, C.G.; King, C.J. The effects of design and operating conditions on particle morphology for spraydried foods. J. Food Process Eng. 1981, 4, 171-187, https://doi.org/10.1111/j.1745-4530.1981.tb00254.x.

37. Lee, K.C.; Yoon, Y.S.; Li, F.Z.; Eun, J.B. Effects of inlet air temperature and concentration of carrier agents on physicochemical properties, sensory evaluation of spray-dried mandarin (Citrus unshiu) beverage powder. Appl. Biol. Chem. 2017, 60, 33-40, https://doi.org/10.1007/s13765-016-0246-8.

38. Yuksel, H.; Dirim, S.N. Application of the agglomeration process on spinach juice powders obtained using spray drying method. Dry. Technol. 2020, 1-16, https://doi.org/10.1080/07373937.2020.1832515.

39. Sun, X.; Cameron, R.G.; Bai, J. Effect of spray-drying temperature on physicochemical, antioxidant and antimicrobial properties of pectin/sodium alginate microencapsulated carvacrol. Food Hydrocoll. 2020, 100, 105420, https://doi.org/10.1016/j.foodhyd.2019.105420.

40. Quek, S.Y.; Chok, N.K.; Swedlund, P. The physicochemical properties of spray-dried watermelon powders. Chem. Eng. Process. 2007, 46, 386-392, https://doi.org/10.1016/j.cep.2006.06.020.

41. Barbut, S.; Harper, B.A. Dried Ca-alginate films: Effects of glycerol, relative humidity, soy fibers, and carrageenan. LWT - Food Sci. Technol. 2019, 103, 260-265, https://doi.org/10.1016/j.lwt.2019.01.004.

42. de la Cruz, A.; Ortega, D.; García-Triana, A.; González-Silva, N.; Solis-Oviedo, R.L. A brief review of edible coating materials for the microencapsulation of probiotics. Coatings 2020, 10, 197, https://doi.org/10.3390/coatings10030197.

43. Campelo, P.H.; Sanches, E.A.; Fernandes, R.V. de B.; Botrel, D.A.; Borges, S.V. Stability of lime essential oil microparticles produced with protein-carbohydrate blends. Food Res. Int. 2018, 105, 936-944, https://doi.org/10.1016/j.foodres.2017.12.034.

44. Goula, A.M.; Adamopoulos, K.G.; Kazakis, N.A. Influence of spray drying conditions on tomato powder properties. Dry. Technol. 2004, 22, 1129-1151, https://doi.org/10.1081/DRT-120038584.

45. Tian, H.; Lu, Z.; Li, D.; Hu, J. Preparation and characterization of citral-loaded solid lipid nanoparticles. Food Chem. 2018, 248, 78-85, https://doi.org/10.1016/j.foodchem.2017.11.091.

46. Iñiguez-Moreno, M.; Ragazzo-Sánchez, J.A.; Calderón-Santoyo, M. An extensive review of natural polymers used as coatings for postharvest shelf-life extension: Trends and challenges. Polymers (Basel). 2021, 13, 3271, https://doi.org/10.3390/polym13193271.

47. Soares, J.P.; Santos, J.E.; Chierice, G.O.; Cavalheiro, E.T.G. Thermal behavior of alginic acid and its sodium salt. Eclet. Quim. 2004, 29, 57-63, https://doi.org/10.1590/s0100-46702004000200009.

48. Fuentes-Ortega, S.; Martínez-Vargas, S.; Cortés-Camargo, A.; Guadarrama-Lezama, Y Gallardo-Rivera, R.; Baeza-Jiménez, R.; Pérez-Alaonso, C. Effects of the process variables of microencapsulation sesame oil (Sesamum indica 1.) by spray drying. Rev. Mex. Ing. Química 2013, 12, 505-511, https://doi.org/10.24275/rmiq/Alim826.

49. Daoub, R.M.A.; Elmubarak, A.H.; Misran, M.; Hassan, E.A.; Osman, M.E. Characterization and functional properties of some natural Acacia gums. J. Saudi Soc. Agric. Sci. 2018, 17, 241-249, https://doi.org/10.1016/j.jssas.2016.05.002.

50. Klein, T.; Longhini, R.; Bruschi, M.L.; De Mello, J.C.P. Microparticles containing guaraná extract obtained by spray-drying technique: Development and characterization. Rev. Bras. Farmacogn. 2015, 25, 292-300, https://doi.org/10.1016/j.bjp.2015.03.010.

51. Beristain, C.I.; Azuara, E.; Tamayo, T.T.; Vernon-Carter, E.J. Effect of caking and stickiness on the retention of spray-dried encapsulated orange peel oil. J. Sci. Food Agric. 2003, 83, 1613-1616, https://doi.org/10.1002/jsfa.1602.

52. Stoffels, P.; Müller, M.J.; Stachurski, S.; Terfrüchte, M.; Schröder, S.; Ihling, N.; Wierckx, N.; Feldbrügge, M.; Schipper, K.; Büchs, J. Complementing the intrinsic repertoire of Ustilago maydis for degradation of the pectin backbone polygalacturonic acid. J. Biotechnol. 2020, 307, 148-163, https://doi.org/10.1016/j.jbiotec.2019.10.022.

53. Kaur, G.; Ganjewala, D.; Bist, V.; Verma, P.C. Antifungal and larvicidal activities of two acyclic monoterpenes; citral and geraniol against phytopathogenic fungi and insects. Arch. Phytopathol. Plant Prot. 2019, 52, 458-469, https://doi.org/10.1080/03235408.2019.1651579.

54. Garcia, R.; Alves, E.S.S.; Santos, M.P.; Viégas, G.M.F.; Fernandes, A.A.R.; dos Santos, R.B.; Ventura, J.A.; Fernandes, P.M.B. Antimicrobial activity and potential use of monoterpenes as tropical fruits preservatives. Brazilian J. Microbiol. 2008, 39, 163-168, https://doi.org/10.1590/S1517-83822008000100032.

55. Zheng, S.; Jing, G.; Wang, X.; Ouyang, Q.; Jia, L.; Tao, N. Citral exerts its antifungal activity against 
Penicillium digitatum by affecting the mitochondrial morphology and function. Food Chem. 2015, 178, 7681, https://doi.org/10.1016/j.foodchem.2015.01.077.

56. Tao, N.; OuYang, Q.; Jia, L. Citral inhibits mycelial growth of Penicillium italicum by a membrane damage mechanism. Food Control 2014, 41, 116-121, https://doi.org/10.1016/j.foodcont.2014.01.010.

57. Tang, X.; Shao, Y.L.; Tang, Y.J.; Zhou, W.W. Antifungal activity of essential oil compounds (geraniol and citral) and inhibitory mechanisms on grain pathogens (Aspergillus flavus and Aspergillus ochraceus). Molecules 2018, 23, 2108, https://doi.org/10.3390/molecules23092108.

58. Simon, H.; Haj-Yehia, A.; Levi-Schaffer, F. Role of reactive oxygen species (ROS) in apopotisis induction. Apoptosis 2000, 5, 415-418, https://doi.org/10.1023/a:1009616228304.

59. Rhim, J.W. Physical and mechanical properties of water resistant sodium alginate films. LWT - Food Sci. Technol. 2004, 37, 323-330, https://doi.org/10.1016/j.lwt.2003.09.008.

60. Zhou, H.; Tao, N.; Jia, L. Antifungal activity of citral, octanal and $\alpha$-terpineol against Geotrichum citriaurantii. Food Control 2014, 37, 277-283, https://doi.org/10.1016/j.foodcont.2013.09.057. 